\title{
ENTENDIENDO LA TRATA NIGERIANA: ANÁLISIS DEL DELITO DESDE UN ENFOQUE DE DIVERSIDAD CULTURAL
}

\author{
Autoras: Esperanza Jorge Barbuzano \\ maspebeleten@gmail.com \\ Universidad Autónoma de Madrid \\ Inmaculada Antolínez Domínguez \\ inmaculada.antolinez@uca.es \\ Universidad de Cádiz \\ Tania García Sedano \\ taniagarciasedano@yahoo.es \\ Universidad Carlos III
}

\section{Resumen}

El objetivo de este artículo es poner en diálogo los elementos del delito de la trata y aquellos aspectos del contexto sociocultural referenciados por las mujeres con las que se ha trabajado. Se ha elegido el contexto nigeriano por ser una de las nacionalidades predominantes de víctimas y tratantes en España y por constituir un problema casi endémico en ese país. 
Este artículo pretende ser una llave que coadyuve a entender a las víctimas y sus condicionantes culturales.

Palabras clave: diversidad cultural; Nigeria; España; trata de seres humanos.

\title{
Understanding Nigerian trafficking: analysis of the crime from a cultural di- versity approach
}

\begin{abstract}
The objective is to bring into dialogue the elements of the crime of trafficking and those aspects of the sociocultural context referenced by the women with whom we have worked. The Nigerian context has been chosen because it is one of the most important nationalities of victims and traffickers in Spain and because it is an almost endemic problem in that country.

This article aims to be a key that helps to understand the victims and their cultural constraints.
\end{abstract}

Key words: cultural diversity; Nigeria; Spain; trafficking in human beings.

Fecha de recepción: 09/02/2019

Fecha de aceptación: 08/07/2019

\section{INTRODUCCIÓN ${ }^{1}$}

La regulación conjunta del tráfico ilícito de inmigrantes y de la trata de seres humanos, artículo 318 bis que estuvo en vigor hasta el año 2010 en nuestro país, no facilitó una adecuada comprensión del fenómeno. Y no lo hizo porque en definitiva y como señala Pérez Alonso (2012) la regulación del delito de trata tenía y, mantiene, un enfoque trafiquista pues el Legislador actúa en clave de política migratoria, instrumentalizando el delito de trata de seres humanos como un escudo

${ }^{1}$ Este artículo es producto de la investigación doctoral de una de las autoras, de los datos producidos en el proyecto "Trata de personas, salud integral y cuidados: mujeres transfronterizas en tránsito de Marruecos hacia Andalucía" de la Universidad Pablo de Olavide, financiado por la Agencia Andaluza de Cooperación Internacional para el Desarrollo (2014-2017), así como de la actividad investigadora incardinada en la Universidad Carlos III de Madrid. 
protector de las fronteras españolas en detrimento de los derechos de las personas que podrían ser víctimas².

Así, hasta el 2010 no se tipifica de forma autónoma el delito de trata de seres humanos en el artículo 177 bis del Código Penal. Por su parte, el año 2011 marca dos hitos de indudable trascendencia en este contexto. Por un lado, se produjo la modificación del artículo 59 bis de la Ley de Extranjería, articulando un régimen especial para las personas víctimas de dicho delito, y estableciendo, fundamentalmente, un incremento de la duración del período de restablecimiento y reflexión. Por otro, se aprobó el Real Decreto 557/2011, de 20 de abril, por el que se aprueba el Reglamento de la Ley Orgánica 4/2000, sobre derechos y libertades de los extranjeros en España y su integración social.

En 2008, España pone en marcha el I Plan Integral contra la trata de seres humanos con fines de explotación sexual centrado en tres objetivos: asistencia social a las denominadas víctimas; lucha efectiva contra las mafias y traficantes; y sensibilización, prevención y coordinación. Sin embargo, desde el mismo año, el Defensor del Pueblo comienza a recoger en sus informes anuales quejas interpuestas por organizaciones de la sociedad civil en relación con la carencia de procedimientos adecuados para proteger a las posibles víctimas, concluyendo con el informe monográfico que la institución presenta en el año 2012 y sus posteriores recomendaciones. Dicho informe marca un hito en la visibilización de la realidad del fenómeno en España, en los desafíos que la protección a las personas en situación de trata presenta (fundamentalmente, desde una perspectiva de derechos humanos) y en los retos que plantea en materia de política pública.

En el mencionado trabajo del Defensor del Pueblo se apunta la nacionalidad nigeriana como una de las más significativas a la hora de abordar la trata de seres humanos con fines de explotación sexual en el territorio español. Siguiendo el Plan Integral de lucha contra la trata de mujeres y niñas con fines de explotación sexual (2015-2018), Rumania es señalado como el país con mayor número de posibles víctimas (32\%) en España, pero seguido de Nigeria (27\%). A nivel europeo, igualmente, la nigeriana aparece como la segunda nacionalidad de víctimas de trata con fines de explotación sexual representando un $18 \%$ del total

${ }^{2}$ Partiendo del hecho de que las mujeres participantes en nuestro trabajo de investigación no se han sentido reconocidas bajo el término "víctima" por el imaginario social des-agenciador que este comporta, utilizamos en este artículo dicho término sólo para aquellos casos en que hacemos referencia a la categoría establecida en la normativa española a partir de la cual se establece un proceso de protección. A propósito, recordamos que, en España, sólo las Fuerzas y Cuerpos de Seguridad pueden llevar a cabo la identificación de una persona como víctima de trata y que, el número de víctimas identificadas en nuestro país es claramente insuficiente. En ese sentido, cabría destacar el dislate existente entre personas detectadas en situación de riesgo que ascienden a 10.111 según el Centro de Inteligencia contra el Terrorismo y el Crimen Organizado en su informe de 2017 y el número de víctimas identificadas que aparecen reflejadas con la cifra de 366 personas según la Fiscalía General del Estado, 2017. 
(EUROSTAT $\left.{ }^{3}, 2016\right)$. De ahí que en el presente artículo nos centremos en la trata principalmente de mujeres y jóvenes de origen nigeriano y, concretamente, procedentes del Estado de Edo por ser la procedencia regional de la mayoría de ellas (UNESCO 4 , 2006; UNODC 5 , 2012).

A partir de lo expuesto, el presente artículo parte de los discursos producidos con un grupo de mujeres y jóvenes nigerianas participantes en nuestro trabajo de investigación, con el objetivo de visibilizar la importancia de algunos elementos y prácticas socio-culturales en el fenómeno de la trata. Consideramos que el manejo de dichos elementos puede facilitar la contextualización y comprensión localizada de las circunstancias que vivencian las mujeres y jóvenes nigerianas vinculadas a la trata de personas. Nos centraremos especialmente en ciertos aspectos que las participantes han señalado en relación con el papel histórico de la migración en la región, los sistemas de creencias y de parentesco, así como la organización familiar. Ello será puesto en relación con los elementos del delito de trata que recoge en su definición el Código Penal español.

Para concluir, esta propuesta parte de la convicción de que el desconocimiento del contexto nigeriano y de sus características socio-culturales puede ayudar a que predominen estereotipos y prejuicios culturales, raciales y de género que, fundamentalmente, hacen que, en ocasiones, no se tutelen y protejan adecuadamente los derechos de las posibles víctimas de trata de seres humanos procedentes de Nigeria en los procesos de identificación y de acompañamiento judicial y social. En ese sentido, nuestro país ha merecido una condena por parte del Tribunal Europeo de Derechos Humanos:

"El Tribunal señala que, en sus denuncias de los días 21 y 25 de julio de 2005, la demandante mencionaba las palabras racistas que le habrían proferido los policías, en particular, "puta negra vete de aquî", y haberles reprochado a los agentes no haber interpelado a otras mujeres que ejercían la misma actividad, pero tenían un "fenotipo europeo". Estos argumentos no fueron examinados por los Tribunales que tenían que entender del caso, que se limitaron a retomar por su cuenta el contenido de los informes del Jefe de Policía de las Islas Baleares, sin efectuar una investigación más en profundidad sobre las actitudes supuestamente racistas" (STEDH 4759/2012 de 24 de julio).

${ }^{3}$ Oficina Europea de Estadística.

${ }^{4}$ Organización de las Naciones Unidas para la Educación, la Ciencia y la Cultura.

5 Oficina de Naciones Unidas contra la Droga y el Delito. 


\section{BREVE ACERCAMIENTO AL DELITO DE TRATA DE SERES HUMANOS}

Como se ha señalado, el delito de trata de seres humanos fue introducido en el ordenamiento jurídico español a través de la Ley Orgánica 5/2010 de 22 de junio, artículo 177 bis. A través de esta reforma se intentó dar respuesta al tratamiento, absolutamente inadecuado, del fenómeno que nos ocupa ${ }^{6}$. En ese sentido, se hacía urgente diseccionar la regulación del delito de inmigración irregular y el de trata de seres humanos para dar respuesta a los distintos compromisos internacionales asumidos por España, como el Protocolo para prevenir, reprimir y sancionar la trata de personas, especialmente mujeres y niños, que complementa la Convención de Naciones Unidas contra la Delincuencia Organizada Transnacional (en adelante Protocolo de Palermo).

Cabe señalar al respecto que recientemente se ha llevado a cabo la última reforma del Código Penal mediante la Ley Orgánica 1/2015 de 30 de marzo con la finalidad de trasponer al ordenamiento jurídico español la Directiva 2011/36/ $\mathrm{UE}^{7}$. Esta incorporación ha sido fundamental puesto que dicha Directiva acoge un enfoque de análisis del fenómeno centrado en la protección de la persona victimizada y de sus derechos, teniendo además una clara perspectiva específica de género.

Los elementos del delito de trata derivan de la definición que de esta se ofrece en el Protocolo de Palermo, así como en la Directiva 2011/36/UE que han sido incorporados a nuestro ordenamiento a través del señalado artículo 177 bis del Código Penal. Estos elementos son articulados a través de los verbos típicos, los medios comisivos y las formas de explotación.

En cuanto a los verbos típicos, se señalan como tales: trasladar, transportar, acoger o recibir personas. Para lo cual se emplean determinados medios comisivos: violencia, intimidación, engaño, abuso de una situación de superioridad o de necesidad o de vulnerabilidad de la víctima nacional o extranjera, o mediante la entrega o recepción de pagos o beneficios para lograr el consentimiento de la persona que poseyera el control sobre la víctima.

Y todo ello, con una finalidad de explotación. Esta incluirá la explotación de la prostitución ajena u otras formas de explotación sexual, imposición de trabajos o de servicios forzados, esclavitud o prácticas similares a la esclavitud, a la

\footnotetext{
${ }^{6}$ La propia Comisión Europea en su Informe de 6 de diciembre de 2006 lamentaba que España no hubiera establecido una distinción clara entre la trata de seres humanos y el tráfico ilícito de emigrantes.

7 Directiva 2011/36/UE del Parlamento Europeo y del Consejo, de 5 abril de 2011, relativa a la prevención y lucha contra la trata de seres humanos y a la protección de las víctimas y por la que se sustituye la Decisión marco 2002/629/JAI del Consejo.
} 
servidumbre o la extracción de órganos. Así mismo, la explotación de la mendicidad, las actividades delictivas, la extracción de órganos corporales y la celebración de matrimonios forzados.

Y concluimos esta aproximación a la definición del delito de la trata señalando que no será exigible la presencia del mismo medio comisivo durante todo el iter delictual (Fiscalía General del Estado, 2011). Al igual que tampoco la confluencia de todos ellos para que se identifique trata de personas. Así mismo, de conformidad con el párrafo 2 del precepto mencionado ${ }^{8}$ si la persona fuera menor de edad no sería precisa, para la consideración del delito de trata, que concurran los meritados medios comisivos.

\section{LA TRATA NIGERIANA EN ESPAÑA}

\section{EL CONTEXTO DE ORIGEN: NIGERIA}

Nigeria es un país situado en África occidental, en la zona del golfo de Guinea, tiene una superficie de $923.770 \mathrm{Km}^{2}$ y una población de 190.886 .311 personas, lo que la convierte en uno de los países más poblados del mundo. Fue protectorado británico desde 1901, para pasar a ser colonia a partir de 1914. La independencia, conformando una federación de tres regiones, la obtuvo en 1960. Sólo 24 años antes fue prohibida definitivamente la esclavitud, comercio este fundamental para la región desde el siglo XIV.

Es un país rico en recursos naturales, fundamentalmente petróleo, pero con una explotación de los mismos gestionada por empresas extranjeras (Royal Dutch Shell, ExxonMobil, Agip, Total S.A. o Texaco), a lo que se suma un importante problema de corrupción interna. Así, la economía nigeriana sigue dependiendo en un $90 \%$ de las exportaciones de petróleo cuyos beneficios, sin embargo, apenas llegan a la mayoría de la población que sobrevive gracias a una agricultura de subsistencia (Okolo, 2019).

Ello sienta las bases actuales para una importante situación de desigualdad social y económica. Circunstancia que se ve agravada exponencialmente en el caso de las mujeres y de las niñas en cierta medida debido a la estratificación por cuestión de género y edad que predomina en concreto en el territorio que nos ocupa y que analizaremos posteriormente. Según el último informe sobre la brecha de género del World Economic Forum (WEF, 2016), Nigeria ocupa el lugar 116 de 144 países. Esta desigualdad y la feminización de la pobreza se desarrollan en un

\footnotetext{
8 "Aun cuando no se recurra a ninguno de los medios enunciados en el apartado anterior, se considerará trata de seres humanos cualquiera de las acciones indicadas en el apartado anterior cuando se llevare a cabo respecto de menores de edad con fines de explotación".
} 
escenario en el cual algunas prácticas sociales y los estereotipos desde donde se acciona imposibilitan la igualdad efectiva según refiere el Comité para la Eliminación de la Discriminación de la Mujer, en el documento de Observaciones finales sobre los informes periódicos séptimo y octavo combinados de Nigeria (CEDAW, 2017). Así prácticas como la mutilación genital femenina, el matrimonio infantil, la poligamia o el levirato, se mantienen vigentes en algunas regiones de este país y colocan a las mujeres en una posición de dominio y agresión.

En relación con la corrupción anteriormente señalada apuntamos que, por lo que se refiere al objeto del presente trabajo, constituye un push factor que coadyuva a la trata de seres humanos, siendo este fundamental para que el fenómeno pueda alcanzar las dimensiones que tiene y que queda reflejado en la connivencia de los estamentos institucionales y funcionariado con las redes o tratantes (UNODC, 2008).

Para concluir esta aproximación al contexto nigeriano, señalamos que en 2015 fue aprobada la ley reguladora de la trata en Nigeria: Trafficking in Persons (Prohibition) Law Enforcement and Administration (Amendment) Act. Esta fue complementada por la National Policy on Protection and Assistance to Trafficked Persons in Nigeria (2008), que supuso la creación de un fondo fiduciario para las víctimas de trata. Al amparo de este marco regulador trabajan entidades e instituciones tanto con la trata interna como con la externa (continental y extracontinental). Sin embargo, el presupuesto asignado al Organismo Nacional para la Prohibición de la Trata de Personas se ha reducido debido a la recesión económica que sufre Nigeria. Un ejemplo de esta disminución de recursos para abordar el fenómeno en origen es que tan solo existían, según la CEDAW (2017) ocho refugios para las víctimas de la trata en el territorio nigeriano, lo que es, claramente, insuficiente.

\section{DATOS SOBRE LA TRATA NIGERIANA EN ESPAÑA}

La frontera sur española constituye una de las puertas de entrada al continente europeo desde África. La relevancia de la nacionalidad nigeriana vinculada con el delito de trata se explicita tanto desde el prisma de las víctimas identificadas como desde la perspectiva de los autores. Así, según la UNODC (2012), la mayoría de las mujeres en trata con fines de explotación sexual, no europeas, detectadas en Europa provienen de África, conformando el 18\% del total las que provienen de Nigeria y en concreto del Estado de Edo (ciudad de Benin) al suroeste de Nigeria. El informe de la UNESCO (2006) señalaba que el 92\% de las víctimas de trata nigerianas provienen de ese Estado.

En España, durante el año 2017, de un total de 366 mujeres identificadas como víctimas de trata de seres humanos, 212 tenían nacionalidad nigeriana (Fiscalía General del Estado, 2017). De este modo, el porcentaje de víctimas mujeres 
nigerianas, en proporción con otras nacionalidades, es superior al 65\%. Así, en el año 2016 de 323 mujeres víctimas de trata, 212 eran nigerianas. La mayoría de las víctimas nigerianas de trata con fines de explotación sexual suelen ser muy jóvenes (entre 18 y 24 años) y mujeres (Fiscalía General del Estado, 2016).

Desde el punto de vista de los sujetos activos del delito, la relevancia de la mencionada nacionalidad es, de nuevo, muy destacable. Así, 131 de las 288 personas investigadas ostentan esta nacionalidad. Por lo que se refiere a las organizaciones o grupos criminales, según se recoge en las memorias de la Fiscalía General del Estado durante el año 2017 se investigó a 14 organizaciones nigerianas, habiendo ascendido en 2018 a 22.

En síntesis, los datos hablan por sí solos. Las mujeres nigerianas constituyen el porcentaje más alto de víctimas de trata extracomunitarias identificadas en nuestro país. Por su parte, los sujetos activos de esta nacionalidad representan casi la mitad de las personas investigadas.

\section{METODOLOGÍA}

En el presente trabajo se ha partido de una investigación cualitativa sustentada en la hermenéutica crítica (Habermas, 2010) reforzando, en todo momento, el protagonismo de las mujeres participantes no sólo desde el reconocimiento de sus relatos experienciales como portadores de conocimientos fundamentales en la materia, sino también haciéndolas partícipes de forma dialógica del proceso de análisis de discurso y de la revisión y generación de resultados.

El método utilizado ha sido eminentemente el etnográfico desde un enfoque multisituado (Marcus, 2011) en diferentes puntos de Nigeria, Marruecos y España, entendiendo que la trata como fenómeno social amplio debe ser abordada más allá de las fronteras de los países. Por ello, se han montado espacios de desarrollo metodológico adaptables yendo allí donde ellas se encontraban (desde centros de acogida a lugares de explotación o asentamientos de población migrante, en cada uno de los territorios) buscando generar espacios de confianza, seguridad y reflexión.

En el diseño metodológico hemos partido de los condicionantes del discurso con los que cuentan las mujeres. Estos refieren a la re-victimización que implica volver a narrar episodios de dolor; la prohibición, bajo amenazas, de contar partes de su relato o de dar cierta información; el hecho, por tanto, de tener un relato construido que es el que saben que deben contar; y, por supuesto, la vulnerabilidad que comporta encontrarse en situación administrativa irregular una vez en Europa. 
Ante dichos condicionantes y frente a esta variedad de contextos diseñamos las herramientas facilitadoras de discurso a partir de tres pilares: el lenguaje creativo (Eisner, 2005), el lenguaje encarnado (Harding, 1996) y el abordaje transversal de los cuidados (Gilligan, 1982). La generación de dichas narrativas ha sido facilitada en talleres donde se ha hecho uso de los diversos lenguajes (verbal, visual, audiovisual o corporal), abordándose la temática desde los cuidados y la salud integral. Este abordaje bordeador se basa en que, en las circunstancias que lo precisen por riesgo para la persona o por posible revictimización discursiva (que suelen ser muy frecuentes), entendemos que no han de ser ellas las que nos cuenten sobre trata de forma directa. En tal caso, deberíamos ser las profesionales las que nos dotemos de los conocimientos y capacidades necesarias para descifrar o leer trata en sus testimonios sin forzarlas a relatarse desde ahí. Por otro lado, consideramos que analizar(se) desde la vertiente del cuidado en detrimento de la habitual línea de la agresión o daños, permite además acompañar a las mujeres en sus procesos de restablecimiento y/o confrontación.

Para este artículo en concreto nos centramos en el análisis de discurso de las narrativas producidas por 18 mujeres nigerianas, con edades comprendidas entre los 18-30 años, que se encuentran actualmente en España. Todas ellas residen en la Comunidad Autónoma de Andalucía, en concreto en las provincias de Cádiz, Sevilla, Granada, Almería y Huelva. De ellas, 8 se encontraban en el momento de la producción de narrativas en recursos de acogida, 4 fuera de la red y en desempleo, y 6 en situación de explotación sexual.

Junto con ello se ha realizado una revisión y análisis de la bibliografía académica y jurisprudencial existente en relación con la trata en Nigeria. Dicha documentación nos ha ayudado a hacer otra aproximación al fenómeno, desde el delito, abordando los elementos típicos, dotándolos de contenido experiencial. Para complementar la mirada se realizaron entrevistas a otros informantes claves (una antropóloga de la Universidad de Benin City, un antropólogo de la Universidad de Calabar y 5 técnicos/as de organizaciones sociales especializadas en trata en Nigeria) lo que posteriormente permitió la triangulación de la información (Gibbs, 2012) desde un análisis múltiple y complementario del fenómeno.

El material discursivo generado por las mujeres ha sido nuestro elemento base de análisis. Este fue almacenado ordenado por capítulos de vida, permitiéndonos hacer una primera lectura sobre las coincidencias, los distanciamientos o las peculiaridades en los relatos. En este momento de estructuración del material se ha contado con la figura de las "revisadoras": jóvenes nigerianas a las que hemos podido ir haciendo devolución de todo avance en la fase de sistematización y primer análisis para contrastarlos o corregirlos con ellas. Este 
ejercicio de revisión con las mujeres atraviesa el proceso completo y permite no sólo redefinir lecturas y resultados, sino que el propio material discursivo producido por ellas esté siempre en movimiento vital, acompasado con los procesos de generación de conocimiento.

En un segundo momento de análisis, se ha realizado la localización y acopio de fragmentos discursivos codificándolos de forma abierta y en relación con cuatro bloques temáticos principales (Charmaz, 2005): cuestiones genéricas relacionadas con la diferenciación étnica por ocupaciones laborales; papel de la migración en la región; aspectos relacionados con el sistema de organización del parentesco y familiar que acoge de forma interseccional la jerarquía de género y edad, los roles familiares y el compromiso colectivo con la familia; y el sistema de creencias en el que, en el caso de la trata nigeriana, cobra un peso muy importante el yuyu o vudú.

Una vez rescatados los verbatim y agrupados en estas categorías, los hemos puesto en relación con lo que se define como delito de trata pretendiendo testar cuánto son escuchados o desoídos ciertos aspectos socio-culturales desde nuestros marcos legislativos y reguladores. El resultado de dicho proceso analítico se expone a continuación dividido en cinco bloques de contenido donde se enuncian ciertos aspectos socio-culturales que, entendemos, se encuentran relacionados con el delito de trata y la intervención sobre el mismo: 1) el papel de ciertos ritos de paso como aquel que otorga nombre a la persona nacida dentro de la familia; 2) el lugar histórico de la libre circulación en la región; 3) la jerarquía de edad como un principio fundamental en la organización social; 4) la relación de ciertos principios de parentesco con la estratificación de género y; 5) el rol del sistema de creencias.

\section{ASPECTOS SOCIO-CULTURALES EN EL ESTADO DE EDO EN RELACIÓN CON EL DELITO DE TRATA}

Pretendiendo reflejar el ejercicio dialógico que hemos realizado en el trabajo de campo con las mujeres que protagonizan este proceso de investigación-acción presentamos, en este apartado, el análisis de algunas claves socio-culturales que ellas han apuntado y que, hemos entendido, abrigan el accionar del delito de trata de personas y los modelos de intervención, en el caso de las jóvenes nigerianas que realizan el trayecto por tierra. 


\section{RITOS DE PASO: EL NOMBRE}

"Cuando un niño o una niña nace se canta una canción. Si alguien desde el camino la escucha sabe que hay un bebé nuevo en la casa. Entonces todos van. Se les ofrece polvo de talco y se lo ponen en sus caras y sus cuellos. Luego bailan. A los catorce días del nacimiento se pone nombres a la persona nacida. Le da nombre el padre, la madre, la abuela, el hermano, el abuelo, el tío... Por ejemplo, yo tengo muchos nombres, todos son míos" (T-S, Huelva, España, 2016). ${ }^{9}$

Cuando trabajamos con las mujeres nigerianas en el ámbito de la investigación y/o de la intervención algo que observaremos pronto es la posibilidad de escucharles diversos nombres para denominarse. Sus traslados geográficos y lo que durante ellos viven, a veces van acompañados de un cambio de nombre. Así, se pueden denominar de forma distinta en el ámbito doméstico y en el espacio público o laboral, en este caso relacionado con las formas de explotación que vivencian. Las razones para que esto suceda son diversas, estando algunas relacionadas con la posible ocultación o coacción de la trata, pero también otras vinculadas a un accionar con agencia sobre su identidad nominativa que está amparado en una práctica cultural. Uno de los ritos de paso más referenciados por importancia y significatividad para las mujeres participantes en este trabajo, fue el de "dar nombre a la persona nacida". En tanto que práctica comunitaria, los ritos de paso implican un cambio de estatus de la persona dentro de la sociedad y ante su grupo (Turner, 1980). En este caso concreto, lo que se festeja y celebra en esta designación múltiple del ser nacido es el hecho de que ha conseguido sobrevivir después de aproximadamente dos primeras semanas (tiempo este que consideran próximo al mundo de los espíritus) y que se encuentra ya en el mundo de los vivos y las vivas siendo, por tanto, uno o una más del grupo social.

Cuando, ya en estas orillas, se acercan o las llevamos a las oficinas acondicionadas de las organizaciones sociales que las atienden o de las Fuerzas y Cuerpos de Seguridad del Estado encargadas de su posible identificación como víctima de trata, no aceptamos poder abrir un expediente, una conversación o un espacio de confianza si no se parte de un nombre único.

En este sentido S. nos narraba: "A mí me gusta mucho el nombre que me dio mi abuela (...) yo cuando llegué aquí he cambiado mi nombre. Yo antes me

\footnotetext{
9 Cuando utilicemos la sigla T. haremos referencia a talleres de creación de narrativas creativas con las mujeres. Cuando usemos la sigla E. nos referiremos, en cambio, al discurso generado en una entrevista. Tanto a la T como a la E le seguirá un guion y el nombre de la persona, siendo este una abreviatura en el caso de precisarse anonimato. En este caso, el fragmento del relato de S. forma parte de la elaboración de su historia de vida, realizado de forma cooperativa con la facilitadora del proceso de producción narrativa e investigadora del proyecto que nos ocupa en este artículo.
} 
llamaba T. pero ahora prefiero este S.” (T-S, Huelva, España, 2015). El riesgo a que una práctica cultural roce el fraude por falsedad de documentación pone alarmas a sonar y la persona que podría haber estado comenzando un proceso de identificación como posible víctima de trata puede pasar a ser cuestionada por un hecho como este. La necesidad de estipular bajo un único nombre identificador el ser social concreto con derechos y obligaciones para poder valorar su caso parece chocar con el travestismo nominativo que conlleva la elección de nombre dentro de sus tránsitos identitarios.

\section{LA MIGRACIÓN EN LOS USOS Y COSTUMBRES}

Si nos colocamos en el Estado de Edo, en tanto que uno de los principales territorios de origen de las jóvenes nigerianas que migran a Europa vinculadas a la trata, y abordamos el tema del movimiento de personas entre territorios que pueden ser o no de un mismo Estado, estaríamos hablando de una concepción ampliamente extendida, donde la libre circulación es un concepto integrado en el derecho derivado de los usos y costumbres (Women's Link Worldwide, 2014; Kabunda, 2006). Hablamos de una región con su geografía marcada por las rutas comerciales, antaño también de esclavos y esclavas, que hoy saludan y ceden trazado a aquellas que son utilizadas por la migración en general y por las mujeres viajeras con las que hemos trabajado en particular.

Señala el antropólogo nigeriano Joseph Okokon Charles, haciendo alusión a la ambición o prácticas habituales y específicas de ciertos grupos étnicos en Nigeria, que "las mujeres (de Edo y Delta) se caracterizan por ser emprendedoras (...) Y una de las formas con las que sienten que pueden hacer mucho dinero es saliendo del país" (E-Charles, Calabar, Nigeria, 2015). Esta práctica tradicional integrada en las formas sustentadoras de las estructuras económicas se ve tamizada por la tupida tela de la concesión de visados. Reflexionando sobre la posibilidad que tienen las mujeres y niñas de viajar con visa, apunta la coordinadora de la entidad nigeriana Girl Power Initiative (GPI) especializada en trata de seres humanos, que: "la mayor parte de ellas son llevadas a Europa por tierra, a causa de la estricta regulación de visados". Y añade, "una persona ve estas dificultades y busca quién le ayude y, ¿quiénes le pueden ayudar?: los tratantes y sus agentes" (E-Osakue, Benin City, Nigeria, 2015).

La política de cierre fronterizo que vive España y Europa en general se ha recrudecido en las últimas décadas. Según Naranjo (2014), desde la firma inicial del Acuerdo de Schengen, se ha establecido una política migratoria común en inmigración y asilo centrada en el control de las fronteras exteriores para combatir la inmigración irregular y las redes de trata. El doble efecto de ello es, por un lado, un fenómeno que Stumpf (2006) denominó “crimigración”, esto es, el 
fortalecimiento de un discurso sobre la migración en relación con diversos delitos como el tráfico ilícito, la trata, el narcotráfico y la seguridad nacional e internacional. Por otro lado, para justificar lo anterior, una mayor inversión presupuestaria en el control y cierre de las fronteras exteriores (Celis \& Álvarez, 2017).

En este contexto, el ejercicio migratorio sustentado en prácticas económicas tradicionales no encuentra escucha en la gestión de las fronteras que se hace allí donde mayormente se dirigen (Europa). De este modo, desde el mismo momento en que las mujeres comienzan su periplo migratorio (de forma "irregular"), están en paralelo recorriendo el camino que las conducirá a una situación de gran vulnerabilidad por razones administrativas. Ello, a su vez, invita a que tengan que convenir con agentes (probablemente vinculados a la trata) una forma alternativa a la legalidad para poder viajar.

\section{EL PAPEL DE LA JERARQUÍA DE EDAD EN EL DELITO DE TRATA DE JÓVENES NIGERIANAS}

Antes de abordar el viaje, con la intención de conocer ciertas lógicas culturales en origen de interés para la trata de personas, vamos a presentar algunos aspectos de la organización familiar y del parentesco que se dan en el Estado de Edo, derivados de los usos y costumbres del reino de Edo o Benin. Concretamente, nos centraremos en las variables de edad y género y su relación con la estratificación social y, unido a ello, el papel de la patrilinealidad, la virilocalidad y de la primogenitura en la herencia.

Respecto a la jerarquía por edad, señala Charles (2014) que entre los yorubas de Nigeria se espera que la persona más joven se postre o tumbe en el suelo frente a una persona de mayor edad como forma de expresar respeto. Es igualmente una demanda cultural en el pueblo ibibio que una persona joven salude a una persona mayor con sus dos manos mientras la persona mayor solo utiliza la mano derecha. Todos estos son ejemplos del papel de la antigüedad en la edad a la hora de establecer jerarquías sociales que históricamente han fundamentado la existencia de los grados de edad en varias regiones africanas. Desde esta lógica, las personas mayores son las custodias de la sabiduría, siendo la edad un atributo importante simbolizada en el pelo blanco. En estrecha relación con ello, Beattie (1980) ha analizado la importancia de los rangos de edad en las formas de organización social y política en diversas regiones de África apuntando a cuatro características básicas: establece grupos corporativos, establece las transiciones, provee de autoridad política y provee de contacto social y cohesión.

"Cada miembro individual pertenece a un grupo de edad con competencias y responsabilidades diferenciadas, pero jerárquicamente establecido en orden descendente. 
El paso de un grado a otro de cada miembro es también fundamental para toda la comunidad: Dirigidos por una consciencia colectiva de servir sin recibir beneficio ni intención de dirigir de forma autocrática a otros, los mayores dan sus consejos de forma gratuita y consultan a los ancestros y realizan rituales para todo el interés de la comunidad" (Charles, 2014, p. 175).

Por contra, los y las más jóvenes deben respeto y obediencia a los y las más mayores como forma de reconocimiento a su sabiduría y liderazgo social.

Trasladada dicha práctica al contexto que nos ocupa en la actualidad, las mujeres participantes en este trabajo señalan el papel de los grupos edad estableciendo una clara deferencia hacia quienes son mayores que ellas en edad y en estatus, pero también en relación con el lugar que se ocupa en la familia: "Mi padre mandaba. Cuando mi madre mandaba, mi padre está muerto. Mi padre tomaba las decisiones y todas nosotras tenía miedo de mi padre" (T-O, Sevilla, España, 2015).

Este ordenamiento estratificado bajo el principio de la edad es común en la sociedad de Benin City, según las mujeres participantes. A toda persona de mayor edad se le debe respeto y obediencia y esta norma cultural no escrita atraviesa la forma de relacionarse y de concebir el orden social en todas etapas del trayecto migratorio: "Ahí tú tienes que hacer lo que ellos dicen porque son más grandes que tú y no puedes hablar. Todo lo que tienes que hacer es callar porque tú ahí no tienes tu familia ni nada” (T-B, Granada, España, 2015).

El abuso de una situación de superioridad, en el marco del delito de trata, refiere la existencia de un desequilibrio de fuerzas entre el autor y la víctima que el autor aprovecha para perpetrar el delito (Requejo, 2015). De ahí que consideremos que el principio de jerarquía y respeto por edad, trasladado a otros contextos como podría ser el transporte en situación de trata por parte de un guide man (guías del camino) o un patrón (hombre responsable del traslado de un grupo), puede ayudarnos a comprender cómo ciertas lógicas culturales pueden facilitar, según las circunstancias, este tipo de abuso no sólo en origen sino también en trayecto o destino. La propia Fiscalía General del Estado en la Circular 5/2011 contempla dicha posibilidad a la hora de plantear distintos supuestos:

"Entre los supuestos de situación de superioridad o vulnerabilidad se comprenderán no solo los que tengan su causa en el pleno sometimiento de la víctima al padre, marido, patriarca o líder comunitario que todavía se producen en determinadas culturas, sino también aquellos en que la víctima se encuentre previamente tratada o en régimen asimilable a la esclavitud" (FGE Circular 5/2011). 


\section{ESTRATIFICACIÓN DE GÉNERO Y FORMAS DE ORGANIZACIÓN DEL PARENTESCO}

En relación con la estratificación de género podemos mencionar ciertos principios de parentesco tales como la ley de primogenitura en la herencia, el patrilinaje y la virilocalidad.

La primogenitura en la herencia, tal y como explican Ugiagbe, Eghafona y Omorogiuwa (2007), viene derivada de la forma de organización del reino de Benin y plantea que el único heredero es el primogénito varón. Se sustenta en la importancia del rol y el estatus, así como en la primacía de los varones sobre las mujeres. Ser el primogénito, en la sociedad benin, implica un estatus adscrito de privilegio comportando derechos, pero también obligaciones. Según Egharevba (1949) este heredará no sólo las posesiones sino también el estatus de su predecesor en la línea de descendencia, así como cierta autoridad sobre sus hermanos y hermanas en tanto que él es el único intermediario entre ellos y sus ancestros. No olvidemos que desde el patrilinaje el trazo del parentesco con el antepasado común va a realizarse de forma unilineal solo por línea paterna, siendo los varones quienes otorgan pertenencia al grupo de parentesco. Si bien es cierto que actualmente existe un marco de flexibilidad en cómo se desarrolla el principio de primogenitura, tal y como señalan Ugiagbe, Eghafona y Omorogiuwa (2007), este forma parte del derecho consuetudinario.

Por otro lado, según la regla de residencia postmarital virilocal, las mujeres al casarse deben abandonar la familia de orientación para ir a vivir con la de su esposo. Señala Kokunre Eghafona, antropóloga de la Universidad de Benin City que "ellas han dejado su propia familia de origen y están casadas en una familia en la que no son nada" (E-Eghafona, Benin City, Nigeria, 2015). Una de las consecuencias de la combinación de dichos principios es que la mujer pierde el vínculo con su familia de orientación y pasa a ocupar un rol de asistencia con estatus inferior, ya no sólo al de sus hermanos, sino también al del marido y su familia. De ahí que, como planteaba Eghafona "el hombre esté muy agarrado a su familia de origen y la mujer es vista, en cambio, como forastera" (E-Eghafona, Benin City, Nigeria, 2015).

La articulación de estos tres principios coloca a la mujer en una situación compleja que socialmente refuerza y reproduce la estratificación de género. Desde la lógica patrilineal, este estatus superior está justificado en tanto en cuanto el varón es el único a través del cual se articula el parentesco, estando a su vez, por la jerarquía de edad, más cercano a sus antecesores cuanto más mayor sea. Este hecho es de gran valor en una sociedad donde la forma de organización social y política sigue estando fuertemente arraigada a la organización del parentesco. Una prueba de ello se encuentra en los procesos de escolarización. Ante la continuidad de los 
estudios, se priorizará a los varones frente a las mujeres ya que, como bien describen las mujeres participantes, ellos van a mantener el apellido de la familia: "Para estudiar se prefiere que sea el niño quien estudie. Porque si el día de mañana se hace médico o tiene buena profesión, es él quien tiene apellido de la familia, lo van a reconocer" (T-Bl, Algeciras, España, 2017). De ahí que, en Nigeria, como en otras regiones, podamos encontrarnos con una tasa de alfabetización menor en niñas (50\%) que en varones (69\%) ocupando Nigeria el lugar 130 de 144 en logro educativo (WEF, 2016).

En dicha estratificación de género juega un papel fundamental los roles y estereotipos de género. Charles (2014, p. 313) plantea que "hombres y mujeres están diferenciados biológicamente, sexualmente y ocupacionalmente para claramente generar un estatus y un rol de subordinación para las mujeres y de superioridad en el estatus y rol de los varones". Entre los roles de género más destacados para el hombre está el ser proveedor, además de ser considerado el cabeza de la familia. La mujer, por su lado, es quien recibe lo que el hombre aporta, y quien atiende y sirve a la familia, a la vez que puede complementar la economía familiar con trabajos de pequeña remuneración. Existe, por tanto, una concepción de la mujer como dadora de servicios (en su familia de origen primero y en la del marido después) que tendrá además la misión de buscar lo que ellas muchas veces nos han denominado "dinero chiquito" que complemente al del hombre.

Cuando falta en la estructura familiar la figura de quien provee (muchas veces relacionado este hecho con los abandonos del marido por vinculaciones a otras mujeres, fallecimientos, etc.) la mujer o la hija seguirá con su rol de servicio o ayuda, pero tendrá que afrontar, además, el deber de proveer, partiendo de las condiciones de desventaja que podemos imaginar según lo expuesto. Vinculando este elemento con el engaño como medio comisivo, con un papel decisivo en la captación, la posibilidad de viajar a Europa para trabajar y apoyar de esta forma a la familia se presenta como una opción para las mujeres nigerianas.

A modo de síntesis de lo expuesto, Eghafona plantea:

"En otras culturas nigerianas las niñas son vistas igual que los niños, y si me caso fuera sigo perteneciendo a mi familia de origen. Pero, en Benin City hay una ley de primogenitura en la herencia. (...) cuando el primer hijo nace, se supone que es el que hereda las propiedades del padre. Los hijos varones son más valorados porque ellos retienen el nombre (...) Entonces, a causa de esto, la mujer suele ser vista como alguien que ofrece ayuda. Trasladando esto a la situación actual, cuando la familia está en una situación de pobreza, es la niña la que es enviada fuera, para que así pueda asistir a la familia” (E-Eghafona, Benin City, Nigeria, 2015).

Por tanto, la combinación de estos elementos colocará a las mujeres en un conglomerado interseccional donde la edad, el género y los roles dentro del sistema 
familiar juegan un papel fundamental en las situaciones de alta vulnerabilidad y necesidad ${ }^{10}$ que vivencian las jóvenes nigerianas y que pueden ser, por tanto, susceptibles de abuso en el marco de la trata de personas. Igualmente, una vez en Europa, estos elementos juegan un papel significativo en la propia vivencia de la coacción que dificulta salir de la situación de explotación. En tanto que mujer, hija, joven y al servicio de la familia, hay un compromiso colectivo en su proyecto migratorio que, en ocasiones, puede rozar la intimidación que dicen vivir:

"La chica no va a estar tranquila con la amenaza del vudú, de la familia, de la madre, de la madame, con todo eso, la chica se va a volver loca. Aunque te entiende, pero se va a hacer más agresiva, va a hacer todo lo posible para salir (del piso de acogida y volver a la explotación)" (T-G, Algeciras, España, 2017).

\section{SISTEMA DE CREENCIAS: EL PROTAGONISMO DEL VUDÚ}

A partir de la última cita del apartado anterior, se muestra el conjunto de agentes que con mayor frecuencia aparecen en sus testimonios implicados en la intimidación que viven estando en territorio de destino y que les limita la posibilidad de abandonar el entramado de la trata. Por intimidación entendemos, según la definición configurada por el Tribunal Supremo, un "constreñimiento psicológico, amenaza de palabra u obra de causar un daño injusto que infunda miedo en el sujeto pasivo" (STS Roj: STS 6445/2002 de 3 de octubre).

En el caso de la trata nigeriana, además de la madame y la propia familia en origen por el compromiso colectivo que implica el proyecto migratorio, hay que tener en cuenta el miedo al que las mujeres aluden cuando relatan sus historias partir de su sistema de creencias y, en concreto, las prácticas rituales vinculadas al vudú o yuyu.

Según la National Agency for Prohibition of Trafficking in Persons (NAPTIP) de Nigeria, en torno a un $90 \%$ de las jóvenes nigerianas que migran a Europa han pasado por un ritual dentro del vudú o yuyu (Wilmott, 2012). De las mujeres participantes en este trabajo, 17 explicitaron abiertamente haber pasado por el ritual de yuyu mayormente en origen y, en menor medida, en algún momento del trayecto. Estas cifras, sin embargo, requerirían de una constante actualización por la mutabilidad en la que dicho fenómeno se encuentra.

Para comprender el sentido del vudú y de sus prácticas relacionadas se hace indispensable entender que todo sistema de creencias se sustenta en una cosmovisión sobre el mundo que le rodea, tanto para explicarlo como para dar respuesta emocional

10 Con respecto a los medios comisivos, consideramos que aquel anunciado como abuso de una situación de necesidad sería prescindible pues presenta el mismo alcance, contenido, naturaleza y significado que la vulnerabilidad, de forma que su incorporación al catálogo no hace sino distorsionar y confundir al operador jurídico al interpretar y aplicar la norma (Daunis, 2013). 
a aquello que no es del todo comprensible. En ese sentido, como menciona Turner (1988), los rituales condensan una lectura global del mundo y la vida, ya que encarnan un discurso de representación simbólico de la realidad socio-natural en la que el grupo se encuentra. Del mismo modo, cumplen una serie de funciones esenciales para la cohesión social, así como para reforzar la pertenencia comunitaria de sus miembros.

Siguiendo a Hadjab (2017, p. 148) el vudú o yuyu "está arraigado en una cosmogénesis animista donde la muerte es la separación del cuerpo como elemento material y del alma como elemento inmaterial, eterno y trascendental”. Como religión animista, se sustenta en una clara creencia en fuerzas de la naturaleza en tanto que espíritus con poderes sobrenaturales a los que se puede pedir su intermediación, tanto para solicitar favores como para ocasionar daños, convirtiéndose de esta forma en susceptibles de veneración. La socialización en este sistema de creencias se da desde el nacimiento teniendo una profunda implementación en el orden social de la sociedad de Benin City. Ello no significa, sin embargo, que no estén surgiendo discursos contestatarios y cuestionadores del poder y la legitimidad del vudú en el territorio, sobre todo, procedentes de otras religiones, en este caso monoteístas, con amplia presencia en Nigeria como son las diversas iglesias cristianas. Sobre este proceso de conflicto inter-religioso una de las mujeres participantes afirmaba: "Yo ya no cree en eso. Yo ahora creo en dios. Si dios quiere que me pase algo, pues bien, pero es por dios, no por el yuyu" (T-B, Granada, España, 2015).

Para el caso que nos ocupa, tal y como apunta Dols $(2017,2013)$, no es tanto la religión vudú la que se encuentra a la base del delito de trata cuanto algunos elementos de esta. Concretamente, apunta a los juramentos rituales donde, a partir del uso de ciertos elementos de la mujer, se sella el contrato entre el tratante, la persona y a veces algún miembro de su familia. Como describía, según su propia experiencia personal, una de las participantes: "Me cogieron las uñas de pies y manos, pelo de la cabeza y me hicieron una foto. Me dijeron que si no pagaba el dinero cuando estuviera en Europa, este yuyu me mataría" (T-B, Granada, España, 2015). Igualmente, este hecho queda reflejado en diversas Sentencias como la que ocupa al fragmento que sigue:

"Antes de emprender el viaje, se sometió a las testigos a un ritual de vudú, en el que les quitaron pelo de la cabeza, vello del pubis, les cortaron las uñas, y tuvieron que jurar que no iban a denunciar a la policía, que iban a pagar la deuda y que no iban a escapar, pues en caso contrario las matarían a ellas y a sus familias" (STAPM Roj: SAP M 6282/2015 de 9 de marzo de 2015).

Es interesante señalar también que, en otras ocasiones, las mujeres apuntan igualmente que en dicho ritual se realizan acciones para atraer la buena fortuna en el viaje, así como para pedir protección en el trayecto. 
En el caso de este juramento ritual es importante mencionar el papel que la familia juega en él, tanto familiares presentes en el mundo de los vivos como los ancestros que se encuentran en otro plano, en tanto que seres a los que se debe especial respeto. Refleja esta circunstancia la Sentencia de la Audiencia Provincial de Vigo cuando establece:

"En ejecución de dicho plan, sus colaboradores en Nigeria captaron a la TP1, la cual procede de una pequeña población de Nigeria donde vivía con sus padres y dos hermanos, bajo la falsa promesa de trabajar en España como modelo y consiguiendo que realizara previamente un ritual de vudú, en el que la TP1 cree firmemente, por el que se comprometía al cumplimiento de sus instrucciones en todo momento, participando en dicho pacto su progenitora y garantizando ambas el cumplimiento de dicho pacto con sus vidas, logrando de esta forma crear un clima de coacción e intimidación suficiente para someter en todo momento la voluntad de la TP1" (STAPV Roj: SAP PO 1019/2017 de 16 de mayo).

Al ser un acuerdo legítimo para la mujer o joven entre todas las partes involucradas y ante los ancestros, si este pacto se rompe las consecuencias para ella o su familia pueden ser múltiples. Según su sistema de creencias estas pueden ir desde la muerte a enfermedades físicas o mentales, entre otras, de ahí el profundo rechazo a realizar cualquier acción que pueda ocasionar la ruptura del juramento. Sobre ello, resulta muy interesante la Sentencia de la Audiencia Provincial de Madrid que refiere:

"Respecto del vudú, como elemento de coacción y amenaza, la Psicóloga Forense Felicidad Inmaculada declaró que está prohibido decir que se tiene miedo del vudú porque eso forma parte del vudú, por eso las testigos han dicho que no creen, aunque sí creen, y la psicóloga Gemma Delia, del Proyecto Esperanza, organización que trabaja con mujeres víctima de trata, precisó que se trata de mujeres que tienen un marco cultural muy diferente al nuestro, y que las ideas en torno a la espiritualidad que tiene África y las mujeres de origen africano es una creencia absoluta en toda la sociedad, creen profundamente porque desde su primera socialización aprenden que eso existe, y en las sesiones que tienen con ellas van contando su miedo al tiempo que dicen "pero yo no creo", hay un conflicto bastante profundo y ciertas normas de que no hablen de eso porque si denuncian van a morir" (STAPM Roj: SAP M 6282/2015 de 9 de marzo).

Por último, como acertadamente señala Nwohu (2008), el carácter intimidatorio que posee el vudú en las jóvenes nigerianas que han vivenciado situaciones de trata no está tanto en el propio ritual en sí cuanto, en la imposibilidad de cumplir con el compromiso acordado, esto es, el pago de la deuda, no contar nada a la policía y asumir las condiciones de explotación. Ello, unido a la propia irregularidad administrativa en la que muchas se encuentran, según señala Nwohu 
(2008) genera una tensión insostenible ante la imposibilidad del cumplimiento del acuerdo. De ahí que dicho juramento adquiera carácter de medio intimidador en las jóvenes nigerianas participantes de la investigación.

Para finalizar, quisiéramos subrayar la cautela que debe presidir el análisis de esta cuestión y ello so pena que, al desacreditar, desde un posicionamiento etnocéntrico, el sistema de creencias de "la otra" o "del otro" nos pueda conducir a dar una lectura de sus prácticas o creencias como incluidas en un engaño asumido por la ingenuidad o la inferioridad de esa otredad. Así, haciendo una generalización, sin mayor pretensión que la de dar una aproximación, el vudú o yuyu de partida no debería entenderse como engaño en los medios comisivos de la trata ya que para quienes vivencian los juramentos rituales vinculados a dicha religión, estos son absolutamente legítimos y verdaderos.

Otra cuestión que merece análisis se refiere al contenido de los acuerdos que se establezcan en la práctica ritual de contrato ya que, en ellos, sí puede haber engaño. Para valorar la idoneidad del engaño como medio capaz de determinar a la víctima deberán considerarse, primero, los criterios objetivos, mediante una valoración ex ante de los medios utilizados para generar el mismo; y, segundo, los criterios subjetivos, es decir, las circunstancias personales de la víctima en cada caso concreto.

El error consecuencia del engaño se puede lograr a través de múltiples formas de la más variada naturaleza. En el caso de la trata nigeriana uno de los engaños destacados es la cantidad estipulada para el pago por el viaje, debido a la falta de comprensión real del significado de esta en un escenario diferente para ellas como es otro continente, otro contexto cultural y en el marco de explotación vinculado a la trata. En ese sentido, hay que subrayar la existencia de un imaginario en el que Europa aparece como un lugar donde es fácil conseguir dinero: "Está preguntando a este hombre, ¿cuánto yo voy a pagar aquí? Él dice 50.000 euros. Pero yo pensar que en España se hace mucho dinero... Yo pensar, cuando yo llegar aquí, dinero hace así, cae mucho (gesticula con las manos como si agarrara dinero que cae del cielo)" (T-O, Sevilla, España, 2015).

Otro engaño frecuente en el marco del mencionado ritual es el objeto del viaje. Es decir, el trabajo a desempeñar para devolver la deuda económica asumida, así como las condiciones de este. En sus testimonios nos muestran que en ningún caso en el juramento que hicieron se reflejó la situación de explotación ni tampoco, en ocasiones, la dedicación al trabajo sexual:

"Ella llega y me dice ¿tú sabes qué vas a hacer aquí? Yo digo tu hermano me ha dicho que cuidar niños o coger tomate en una finca. Ella me dice "cállate". Y trae un desodorante y preservativo. Y dice, "así, se pone asî". Y yo digo, ¿qué? Y dice, "sí, tú vas a hacer prostituta" (T-O, Sevilla, España, 2015). 


\section{CONCLUSIONES}

España constituye uno de los puntos fundamentales de las rutas migratorias desde África hacia Europa, muchas veces, desde cauces irregulares ante el cierre de fronteras que está reforzando el continente europeo. Por ello, se entiende como esencial una identificación ágil de aquellas personas susceptibles de protección internacional y aquellas otras que pudieran ser víctimas de trata (Defensor del Pueblo, 2015).

Cuando señalamos la necesidad de establecer procedimientos adecuados para la identificación no sólo pretendemos apuntar a la idoneidad de los métodos o protocolos para poder alcanzar las más altas cifras, que también, sino que además esto se haga desde la premisa de protección y cuidados tanto a dichos procesos como, y, sobre todo, a las personas que participen en ellos.

A este respecto, es recurrente el señalar la necesidad de la no revictimización de quienes comienzan el itinerario de identificación, por lo que se manejan ya en las entidades e instituciones especializadas diversos criterios de partida como: intentar evitar que la persona cuente su relato de vida a distintos profesionales para procurar que el complejo proceso de producción biográfica lo experimente el menor número de veces, sobre todo teniendo en cuenta los frecuentes episodios de daño y agresión o el estrés que puede suponer debido a la posible prohibición a hacerlo; que cuando acceda a contar se haya establecido un contexto adecuado de confianza, tranquilidad y seguridad, que a su vez respete el proceso de restablecimiento de la persona; etc. Al margen de que estas premisas se den con mayor o menor frecuencia en nuestros procedimientos, lo que a este artículo compete es proponer que a ello se le añada la inclusión de un enfoque sensible a la diversidad socio-cultural por parte de las y los profesionales que tengan como labor la facilitación de los procesos de construcción del relato de vida de las posibles víctimas de trata.

Recordemos que sigue siendo fundamental, y casi imprescindible, que estas cuenten sus historias para poder localizar en ellas los conocidos indicadores de trata o de protección internacional. Para la construcción de este relato entendemos importante establecer espacios dialógicos adecuados en los que se haga uso no sólo de una lengua común, sino que se maneje o se tenga en cuenta el imaginario socio-cultural que abriga la narración de la persona.

No hablamos de identidades determinadas y esencializadas por las culturas de origen, ni mucho menos. Partimos del movimiento como esencia de la construcción cultural del ser y de la sociedad donde nuestras raíces también se mueven de lugar (atravesando rutas migratorias) viéndose afectadas y modificadas. Así, los aspectos socio-culturales que manejamos se tendrán que ir nutriendo de aquellos que las propias mujeres van adquiriendo a lo largo de la experiencia. Por ello, 
trabajar con ellas, nos permite aprender de ellas, con ellas. No sólo las mujeres están transitando, sus identidades y por ello sus imaginarios se conforman en continuo proceso de cambio. Hacer el recorrido de vida que ha hecho cada una de las mujeres para manejar sus claves sólo puede ser planteado si comprendemos como tal el ejercicio de escucha legitimadora de sus relatos preñados de significados.

Así, en ese proceso de identificación de posibles víctimas de trata o solicitantes de asilo, defendemos en este artículo la importancia de un enfoque de diversidad cultural por parte de las fuerzas y cuerpos de seguridad, así como por parte del personal técnico de las organizaciones que acompañan y asisten estos procesos. Dicho enfoque, entendemos, permitiría comprender con mayor complejidad y profundidad las cosmovisiones y sistemas culturales diversos que conforman a la persona y que, de alguna manera, también podrían ayudar en el proceso de intervención que se realizase con ella, tanto social como jurídico.

Por último, concluimos la importancia de poner en relación el marco jurídico con la realidad socio-antropológica que atraviesa el fenómeno de la trata de personas. Por una parte, consideramos que para legislar sobre el fenómeno y crear protocolos de intervención tenemos que comprender no sólo los elementos del delito sino también los orígenes de dichos elementos, los contextos en los que se ponen en marcha, cómo las personas los leen y los vivencian, y cuáles son las relaciones entre ellos. De ahí el valor en este artículo del trabajo de campo realizado con las mujeres (además de con los/as profesionales de organizaciones y la revisión de las fuentes bibliográficas) para descifrar, con ellas, claves contextualizadas, localizadas y encarnadas que nos han ayudado a comprender la trata como un proceso multilocalizado.

Así, desde un prisma normativo y en relación con todo lo expuesto, proponemos partir del reconocimiento del papel que la libre movilidad, recogido en el Artículo 13 de la Declaración Universal de los Derechos Humanos y otros textos internacionales, tiene en diversas regiones del África Occidental. En contraposición, las políticas de restricción de visados adoptadas por España y Europa están coadyuvando el uso de canales irregulares para la migración con su consecuente vinculación a las redes de trata para el caso de las mujeres nigerianas. Así mismo, esta situación administrativa irregular de llegada al territorio de destino es una base que condiciona los márgenes de acción entre los que podrán moverse.

Debemos recordar que en el supuesto de que la víctima se encuentre en dicha situación irregular en nuestro país (lo que ocurre en la mayoría de los casos nigerianos) la protección de esta se condiciona a su colaboración con las autoridades. Sin embargo, el propio estatus migratorio constituye una de las razones, como hemos planteado, que explicarían la falta de voluntad de las víctimas a denunciar la situación en la que se pueden encontrar y a cooperar con las autoridades de investigación y procesamiento. Esta decisión de no cooperar con las 
autoridades en la investigación del delito podría tener como consecuencia su expulsión del territorio nacional, salvo que haya obtenido un permiso de residencia por circunstancias excepcionales.

Los resultados arrojados por el sistema vigente no son óptimos pues en general, el número de procesamientos por trata de seres humanos sigue siendo extremadamente bajo y a ello debe adicionarse la alta probabilidad de que las víctimas de trata expulsadas sean, de nuevo, vinculadas a la trata una vez llegan a su país de origen, situación que se conoce como re-trafficking. Como se ha presentado en este artículo, el control ejercido sobre ellas o sus familiares, la deuda que pueden no haber terminado de pagar o las propias condiciones de desigualdad y vulnerabilidad en sus contextos, reforzarían esta hipótesis. Esta posibilidad del re-trafficking debiera ser tenida en cuenta a la hora de argumentar la protección internacional en los casos que corresponda.

Igualmente, consideramos que sería idóneo que la identificación no fuese exclusivamente competencia de las fuerzas y cuerpos de seguridad del estado sino de un organismo público especializado y multidisciplinar que pueda abordar la complejidad del fenómeno colocando los derechos de la persona como norte guía de la intervención. A lo que debemos añadir la necesidad de desvincular la protección de las víctimas y la Ley de Extranjería. De este modo, el Estatuto de la víctima constituiría una norma óptima para ello.

Por último, España precisa una ley integral contra la trata de seres humanos que aborde el fenómeno desde su globalidad y complejidad, con sus distintas formas de explotación, y contemplándose los múltiples perfiles de personas que lo experimentan. Y, que adopte medidas coherentes e integrales para garantizar la implementación de una política acorde con los compromisos internacionalmente asumidos por nuestro país donde los Derechos Humanos tomen el protagonismo que corresponde.

\section{BIBLIOGRAFÍA}

Beattie, J. (1980). Other Cultures: Aim Methods and Achievement in Social Anthropology. London, England: Routledge \& Kegan Paul.

Celis, R. \& Álvarez, V. (2017). Refugiadas. La trata con fines de explotación sexual en el contexto de militarización y cierre de fronteras. Bilbao: CEAR Euskadi.

Charles, J. O. (2011). Ethnography of African Societies: Sub-Saharan Region. Calabar, Nigeria: University of Calabar Press.

Charmaz, K. (2005). Grounded theory in the 21st Century. En Denzin, N. K. \& Lincoln, Y. S. (eds.), The SAGE handbook of qualitative research. London, England: Sage Publication. 
Comité para la Eliminación de la Discriminación de la Mujer. Observaciones finales sobre los informes periódicos séptimo y octavo combinados de Nigeria. Documento: CEDAW/C/NGA/7-8.

Daunis A. (2013). El delito de trata de seres humanos. Colección delitos, 104. Valencia, España: Tirant lo Blanch.

Defensor del Pueblo (2012). La trata de seres humanos en España: víctimas invisibles. Madrid: Defensor del Pueblo.

Defensor del Pueblo (2015). Informe anual. Disponible en: https://www.defensordelpueblo.es/informe-anual/informe-anual-2015/

Dols, A. (2017). Tratamiento jurídico-penal de los abusos vinculados a la creencia y ejercicio de la brujería y vudú en España (Especial referencia al delito de trata de seres humanos). Tesis Doctoral. Departamento de Derecho Penal. Universidad de Extremadura.

Dols, A. (2013). Voodoo, Witchcraft and Human Trafficking in Europe. Geneva: UNCHR.

Egharevba, J. (1949). Benin Law and Custom. Port Harcourt: Niger Press.

Eisner, E. W. (2005). El arte de las ciencias sociales. Revista Enfoques Educacionales, 7 (1), 81-91.

Gibbs, G. (2012). El análisis de datos cualitativos en investigación cualitativa. Madrid: Morata.

Gilligan, C. (1982). In a different voice. Psychological Theory and Women's Development. Cambridge, Estados Unidos: Harvard University Press.

Habermas, J. (2010). Teoría de la acción comunicativa. Madrid: Trotta.

Hadjab, H. (2017). Las nuevas generaciones de personas menores migrantes. Universidad de Granada. Departamento de Antropología Social. Tesis doctoral.

Harding, S. (1996). Ciencia y Feminismo. Madrid: Morata

MSSSI (2015). Plan Integral de Lucha contra la Trata de Mujeres y Niñas con fines de explotación sexual. 2015-2018. Ministerio de Sanidad, Servicios Sociales e Igualdad.

Naranjo, G. (2014). Desterritorialización de fronteras y externalización de políticas migratorias. Flujos migratorios irregulares y control de las fronteras exteriores en la frontera España-Marruecos. Estudios Políticos, 45, 13-32.

Nwogu, V. (2008). Human Trafficking from Nigeria and Voodoo. Any connections? La Strada International Newsletter, 9.

Okolo, P. (2019, 14 de febrero). Nigeria, un gigante económico que levanta cabeza tras la crisis del petróleo. La Vanguardia. Disponible en: https://www. lavanguardia.com/politica/20190214/46464152437/nigeria-un-gigante-economico-que-levanta-cabeza-tras-la-crisis-del-petroleo.html

Pérez, E. J. (2012). El delito de trata de seres humanos: regulación internacional, europea y española. En Lara, A. (dir.), Nuevos retos en la lucha contra la trata 
de personas con fines de explotación sexual: un enfoque multidisciplinar. Madrid: Marcial Pons.

Requejo, T. (2015). El delito de trata de seres humanos en el Código Penal español. En Alcacer Guirao, R., Martín Lorenzo, M. \& Valle Mariscal de Gante, M. (eds.), La trata de seres humanos: Persecución y Protección de las víctimas. Madrid: Edisofer.

Stumpf, J. (2006). The Crimmigration Crisis: Immigrants, Crime, and Sovereign Power. American University Law Review, 2, 367-419. Disponible en: http://digitalcommons.wcl.american.edu/cgi/viewcontent.cgi?article $=1274 \&$ context=aulr

Turner, V. W. (1980) [1967]. Símbolos en el ritual ndembu. En La selva de los símbolos (pp. 21-52). Madrid, España: Siglo XXI.

Ugiagbe, E.O., Eghafona, K.A. \& Omorogiuwa, T.B.E. (2007). An evaluation of the principles of primogeniture and inheritance laws among the Benin People of Nigeria. Journal of Family History, 32 (1), 1-12.

UNESCO (2006). Human Trafficking in Nigeria: root causes and recommendations. Policy Paper, 14 (2).

UNODC (2012). Global Report in Trafficking in Persons. Disponible en: https:// www.unodc.org/unodc/data-and-analysis/glotip.html

Wilmott, E. (2012). Africa: A Bewitching Economy - Witchcraft and Human Trafficking. Allafrica. Disponible en: https://allafrica.com/stories/201209181007.html

Women's Link Worldwide (2014). La trata de mujeres y niñas nigerianas: esclavitud entre fronteras y prejuicios. Disponible en: http://www2.womenslinkworldwide. org $/$ wlw/new.php?modo $=$ detalle_proyectos $\& d c=72$

World Economic Forum (WEF) (2016). The Global Gender Gap Report. Disponible en: http://www3.weforum.org/docs/GGGR16/WEF_Global_Gender_ Gap_Report_2016.pdf

\section{ANEXO DE JURISPRUDENCIA}

Audiencia Provincial de Madrid. Sentencia Roj: SAP M 6282/2015 de 9 de marzo de 2015.

Audiencia Provincial de Vigo. Sentencia Roj: SAP PO 1019/2017 de 16 de mayo de 2017.

Fiscalía General del Estado. Notas informativas y diligencias de seguimiento del delito de trata de seres humanos. Madrid, 2011.

Fiscalía General del Estado. Circular 5/2011. Sobre criterios para la unidad de actuación especializada del Ministerio Fiscal en materia de extranjería en inmigración. Madrid, 2011. 
Fiscalía General del Estado. Notas informativas y diligencias de seguimiento del delito de trata de seres humanos. Madrid, 2015.

Fiscalía General del Estado. Notas informativas y diligencias de seguimiento del delito de trata de seres humanos. Madrid, 2017.

Tribunal Europeo de Derechos Humanos, asunto B. S. C. España, Sentencia de fecha 24 de julio de 2012. Demanda no 47159/08. Párrafos 70 y 71.

Tribunal Supremo (sala de lo Penal, Sección 2ํㅜ). Sentencia Roj: STS 6445/2002 de 3 de octubre de 2002.

\section{ANEXO DE LEGISLACIÓN}

Directiva 2011/36/UE del Parlamento Europeo y del Consejo, de 5 abril de 2011, relativa a la prevención y lucha contra la trata de seres humanos y a la protección de las víctimas y por la que se sustituye la Decisión marco 2002/629/JAI del Consejo.

Ley Orgánica 4/2000, sobre derechos y libertades de los extranjeros en España y su integración social. "BOE" núm. 10, de 12/01/2000.

Ley Orgánica 5/2010, de 22 de junio, por la que se modifica la Ley Orgánica 10/1995, de 23 de noviembre, del Código Penal. "BOE” núm. 152, de 23/06/2010.

Ley Orgánica 1/2015, de 30 de marzo, por la que se modifica la Ley Orgánica 10/1995, de 23 de noviembre, del Código Penal. "BOE” núm. 77, de 31/03/2015.

Real Decreto 557/2011, de 20 de abril, por el que se aprueba el Reglamento de la Ley Orgánica 4/2000, sobre derechos y libertades de los extranjeros en España y su integración social. 